In the dark they quickly fell down, without growth. Cunsidering these results we are brought to conclude that without light, the synthesis operated by green plants free from carbonic acid in artificial starchy soil becomes impossible. This synthesis therefore appears as a chlorophylian function. Thus the chlorophylian
assimilation may be a work of synthesis essentially, assimilation may be a work of synthesis essentially,
being accompanied, it is true, in ordinary growth with escapes at their edges, thus adding the effect of a re action engine to that of the turbine, and also partl preventing the formation of eddies. The power ma be furnished by an explosive mixture or by steam from a Serpollet boiler. As the turbine may be subjected, without injury, to shocks and high temperatures an is the simplest, lightest, and most easily controlled of motors, it is the best one for this use, and, being mad they rest only on theory and calculation? Only practical experiments, carried on persistently in spite of repeated failures, will attain the goal. The cost of a few failures ought not to frighten the true-hearted pioneer, for no victory was ever yet won without sacrifice, and success in this case would be the most glorlous triumph of the human mind. Only the most careful testing of sound theories and the proper utiliza.

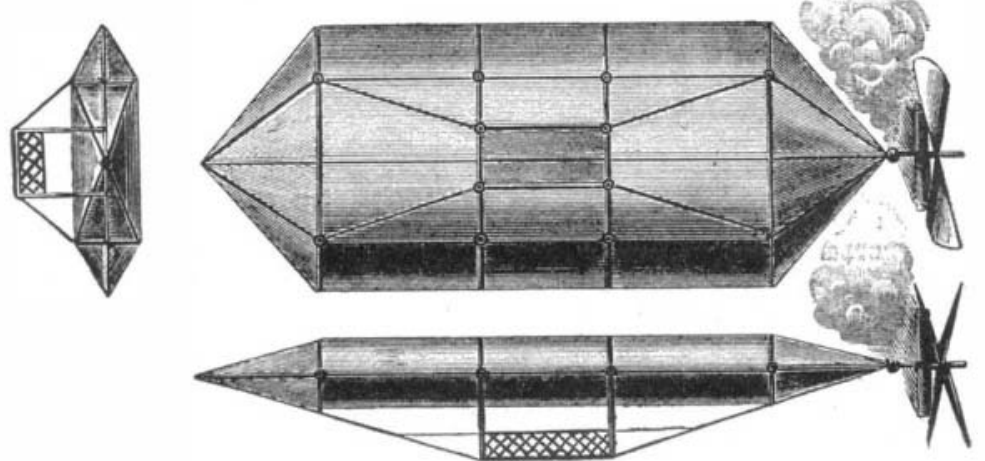

FIG. 1.

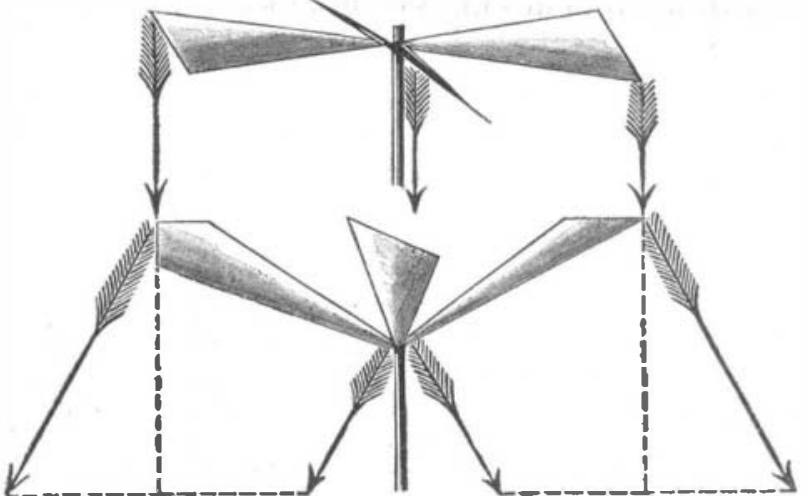

FIG. 2. carbonic acid, by the double exchange of gases, that is, absorption of carbonic acid and disengagement gen, which is characteristic of that assimilation.

\section{A PRoposed SOLUtion OF THE PROBLEM OF FLIGHT.}

\section{By franz Pabisch.}

IT seems almost incredible that our highly developed technical skill has not produced an aerial vehicle that is at all practical. The reasons are, probably, that ignorant and unscientific experimenters have injured the cause, and that the method indicated to us by the birds, and used and improved by them through countless ages, has been neglected. We find in nature various modes of fiying, but never the action of the screwpropeller, balloon, or kite, alone. Wing action combines all methods and such a combination and result should be the object of the aeronaut. Extreme lightness, stability, great power and automatic control are the fundamental conditions of success.

We shall see how well the proposed apparatus shown in Fig. 5 satisfies these conditions. First, however, some technical explanations are necessary.

For the navigation of the air two vehicles are available: the gas balloon, which is lighter than the lower stratum of air and floats upon it, and the flying machine, which must be kept in suspension by a motor. There is still a great difference of opinion among aeronauts concerning the respective merits of the two vehicles. The recognition of the impossibility of steering a spherical balloon has led to the adoption of cigarshaped balloons, with which partial success has been attained. But perhaps the best result possible can be reached with the flat balloon of which three views are reached with the flat balloon of which three views are shown in Fig. 1. The silk-covered skeleton of steel tubes and wires has a broad bearing surface while its sharp edges offer little resistance to the air. The screw propeller, driven by a turbine or electric motor should be mounted on a ball and socket joint and dirigible from the car, makng rudders unnecessary. Still, however, a satisfactory solution of the problem is scarcely to be expected from balloons. Flying ma-
chines which depend wholly on wings or screw propelchines which depend wholly on
lers promise much better results.

In the propeller (Fig. 2, above) two or more inclined blades turn swiftly about a vertical axis and clined blades turn swiftly about a vertical axis and action of the air particles which they set in motion. Fig. 2 (below) shows a construction which has not yet been employed but which should be particularly yet been employed but which should be particularly are here inclined to the axis of rotation. This arrange-

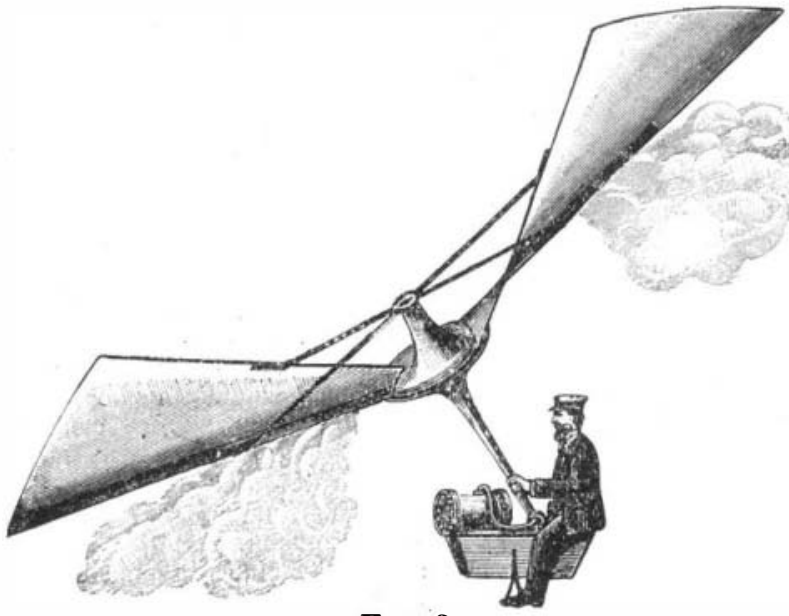

FIG. 3.

ment greatly increases the air resistance for a give diameter of the screw, providing a base of support in the form of an annular conical frustum whose cros section steadily increases as it is followed downward. The effect, therefore, is like that of the flapping of wings. Fig. 3 shows such a screw-propeller driven by a turbine aided by reaction. The steam, or the explosive mixture, enters the turbine through the hollow axis, and then passes through the hollow blades an of sheet steel, it offeris a stable base of attachment for the propeller. A single propeller, mounted on a ball and socket joint, would serve for support, propulsion, and steering, and the weight of the aeronaut would enable the center of gravity to be shifted, as occasion demanded.

From the nature of the molecular movements of the air very favorable predictions may be made for flying machines with moving wings. At the commencement of the downward stroke the base of support is far greater than the area of the wing, and at the end of 列

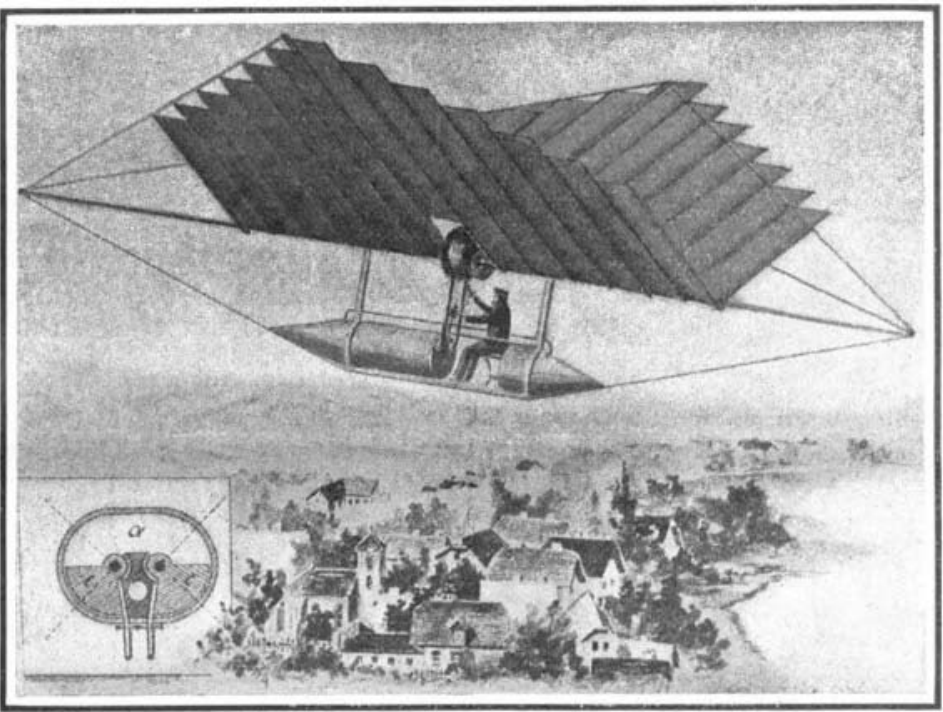

Fia. 5.

mental data. concerning the action of wings, owing to the delicate mechanism involved and the effects of inertia brought into play in the changes of direction of heavy and swiftly moving wings. There can be no doubt, however, of the possibility of overcoming, by steering, these difficulties, which have

Fig. 5 shows a winged flying machine which seems to satisfy the necessary conditions most fully. The lon tubular axis of the apparatus carries the peculiar cillating engine shown in section below. of lightness the shown in section below. For the sake of lightness the cylinder and the two pistons are made of pressed nickel steel. The bent piston rods.terminate n the arms which work the wings. The ends of these arms are connected by steel wires to the ends of the axis of the machine and the areas thus marked off ar filled with adjustable "blinds" of very thin sheet steel. In the upstroke of the wing these blinds open to a certain angle, allowing air to pass through from above and tain angle, allowing air to pass through from above and tion. In the downstroke they are closed and a lifting tion. In the downstroke they are closed and a lifting cal plane are controlled automatically by the compressed air escaping from the pointed ends of the two large cylinders. Steering in a horizontal plane is eflarge cylinders. Steering in a

For the soul of the apparatus, the source of energy, For the soul of the apparatus, the source of energy, able as fuel, is particularly well adapted, though exable as fuel, is particularly well

plosive mixtures may be employed. The powerful downstroke of the $\cdot$ wings is effected by means of the compressed air contained in the upper part of the cylinder and the vapor is used only for the upstroke. This secures economy in working. The
boiler, of spiral steel tubes, is tested to fifty atmosboiler, of spiral steel tubes, is tested to fifty atmos-
pheres and even in the case of a breakdown of the pheres and even in the case of a breakdown of the engine a sudden fall is prevented by the parachute action of the wings which are then directed downward.
In landing and in violent gusts of wind safety is asIn landing and in violent gusts of wind safety is as sured by the

In this machine propelling, steering, and gliding are combined in a simple manner, as in the fiight of a bird, and its practical success is therefore almost assured. But of what use are the most beautiful schemes if tion of the necessary means can secure the splendid results that are possible.-Translated from Steln der Weisen for the ScifnTific AMerican SuppLemevi.

TRANSPORTATION ROUTES AND SYSTEMS OF
THE WORLD.

"THE Transportation Routes and Systems of the World" is the title of a monograph just issued by the Department of Commerce and Labor through its $\mathrm{Bu}$ reau of Statistics. It includes, in addition to statistical statements showing the development of transportation facilities on land and sea, a map by which is presented a bird's-eye view of the world's principal railway and steamship routes and the auxiliary relationship which one bears to the other.

Many maps showing vessel routes on the ocean have been published, also many maps showing the railways of the principal countries. but few if the railways of the pros have been made to show even in outline in a single map the great transportation routes and systems of the entre map, in conjunction with its accompanying tables, presents in outline a combination co the regarding land and water routes usually found only in separate form in other publicaf trans ply outlines in condensed form a few of the great high-

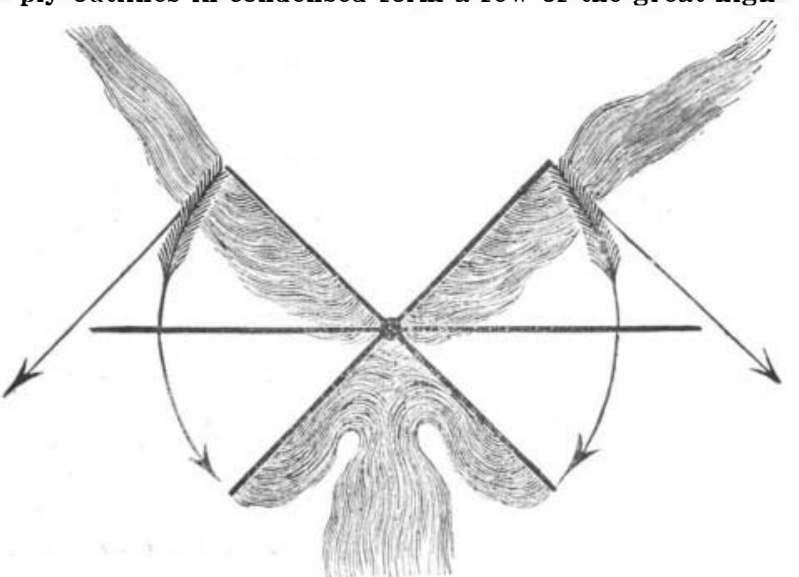

FIG. 4

ways of commerce by land and sea in combination. This seems especially appropriate at this time whe the land and water transportation systems of the worl are offering facilities by which the producer or merchant in the interior of one continent may ship his merchandise from his own door to that of the consignee in the far interior of another continent upon a through bill of lading, and therefore with a knowledge of the cost of transportation from his own establish- 